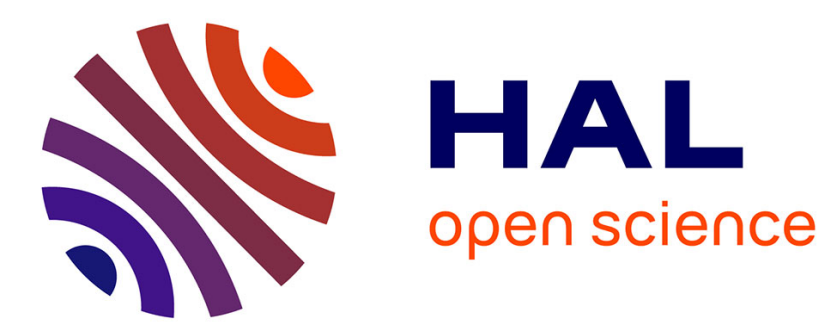

\title{
Mutations linked to interstitial lung disease can abrogate anti-amyloid function of prosurfactant protein $\mathrm{C}$
}

Charlotte Nerelius, Emily Martin, Siwei Peng, Magnus Gustafsson, Kerstin

Nordling, Timothy E Weaver, Jan Johansson

\section{To cite this version:}

Charlotte Nerelius, Emily Martin, Siwei Peng, Magnus Gustafsson, Kerstin Nordling, et al.. Mutations linked to interstitial lung disease can abrogate anti-amyloid function of prosurfactant protein C. Biochemical Journal, 2008, 416 (2), pp.201-209. 10.1042/BJ20080981 . hal-00479025

\section{HAL Id: hal-00479025 \\ https://hal.science/hal-00479025}

Submitted on 30 Apr 2010

HAL is a multi-disciplinary open access archive for the deposit and dissemination of scientific research documents, whether they are published or not. The documents may come from teaching and research institutions in France or abroad, or from public or private research centers.
L'archive ouverte pluridisciplinaire HAL, est destinée au dépôt et à la diffusion de documents scientifiques de niveau recherche, publiés ou non, émanant des établissements d'enseignement et de recherche français ou étrangers, des laboratoires publics ou privés. 


\section{MUTATIONS LINKED TO INTERSTITIAL LUNG DISEASE CAN ABROGATE ANTI- AMYLOID FUNCTION OF PROSURFACTANT PROTEIN C}

Charlotte Nerelius ${ }^{\#}$, Emily Martin ${ }^{\S}$, Siwei Peng ${ }^{\#}$, Magnus Gustafsson ${ }^{\#}$, Kerstin Nordling ${ }^{\#}$, Timothy Weaver $^{\mathcal{S}}$ and Jan Johansson ${ }^{\#+}$

\#Department of Anatomy, Physiology and Biochemistry, Swedish University of Agricultural Sciences, The Biomedical Centre, S-751 23 Uppsala, Sweden, ${ }^{\S}$ Division of Pulmonary Biology, Cincinnati Children's Research Foundation, Cincinnati, Ohio 45229-3039

${ }^{+}$Corresponding author: tel. +46-18-4714065, fax +46-18-550762, e-mail: jan.johansson@afb.slu.se

Short title: ProSP-C self-guards against amyloid formation

The abbreviations used are: ER, endoplasmic reticulum; MALDI, matrix-assisted laser desorption ionization; SP-C, surfactant protein C; ILD, interstitial lung disease; PAP, pulmonary alveolar proteinosis; CTC, C-terminal part of proSP-C; SDS, sodium dodecyl sulphate; wt, wildtype 


\section{Synopsis}

The newly synthesized surfactant protein $\mathrm{C}$ precursor (proSP-C) is an integral endoplasmic reticulum (ER) membrane protein with a single metastable polyVal $\alpha$-helical transmembrane domain that comprises two thirds of the mature peptide. More than 20 mutations in the ER-lumenal, C-terminal domain of proSP-C (CTC), are associated with interstitial lung disease (ILD), and some of the mutations cause intracellular accumulation of cytotoxic protein aggregates and a corresponding decrease in mature SP-C. Here it is shown that (i) human embryonic kidney cells expressing the ILD associated mutants proSP$\mathrm{C}^{\mathrm{L} 188 \mathrm{Q}}$ and proSP-C $\mathrm{C}^{\Delta \mathrm{Exon4}}$ accumulate Congo red positive amyloid-like inclusions, while cells transfected with the mutant proSP-C ${ }^{\mathrm{I} 73 \mathrm{~T}}$ do not, (ii) transfection of CTC into cells expressing proSP-C ${ }^{\mathrm{L} 188 \mathrm{Q}}$ results in a stable CTC/proSP-C $\mathrm{C}^{\mathrm{L} 188 \mathrm{Q}}$ complex, increased proSP-C $\mathrm{C}^{\mathrm{L} 188 \mathrm{Q}}$ half life and reduced formation of Congo red positive deposits, (iii) replacement of the metastable polyVal transmembrane segment with a stable polyLeu likewise prevents formation of amyloid-like proSP-C ${ }^{\mathrm{L} 188 \mathrm{Q}}$ aggregates, and (iv) binding of recombinant CTC to non-helical SP-C blocks SP-C amyloid fibril formation. These data suggest that CTC can prevent the polyVal segment of proSP-C from promoting formation of amyloid-like deposits during biosynthesis, by binding to non-helical conformations. Mutations in the Brichos domain of proSP-C may lead to ILD via loss of CTC chaperone function.

Key words: protein folding; misfolding disease; chaperone; Brichos domain; propeptide 


\section{INTRODUCTION}

Human lung surfactant protein C (SP-C), an hydrophobic, 35-residue acylated transmembrane peptide, is synthesized as a 197-residue proprotein (proSP-C) that undergoes multiple proteolytic cleavages [1]. The mature SP-C peptide corresponds to residues 24-58 of proSP-C (Figs. 1 and 7) and is flanked by an Nterminal propeptide important for trafficking and stability of the proprotein in the secretory pathway [2, 3], and a C-terminal domain with unknown function. In the lung, proSP-C is expressed only in alveolar type II epithelial cells and is anchored in the endoplasmic reticulum (ER) membrane in a type II orientation (C-terminal in the ER lumen) [4, 5]. SP-C, together with SP-B and phospholipids, are secreted into the alveoli and are responsible for lowering the surface tension at the air/liquid interface, thereby preventing alveolar collapse at end expiration [6].

SP-C, and hence also proSP-C, contains a polyVal stretch that forms a transmembrane $\alpha$-helix. This helix is composed of amino acids with a high propensity to form $\beta$-strands [7]. The SP-C helix is consequently metastable in solution and can spontaneously convert into $\beta$-sheet aggregates and amyloid fibrils $[8,9]$. SP-C fibrils have been observed in the alveoli of pulmonary alveolar proteinosis (PAP) patients, but not in healthy controls [9]. Replacement of the SP-C polyVal segment with polyLeu abolishes aggregation and fibril formation [7].

ProSP-C contains a domain known as Brichos, corresponding to residues 94-197. Brichos domains contain about 100 amino acids and are found in several proteins associated with degenerative and proliferative diseases, such as Bri, associated with amyloid formation and familial British and Danish dementia, and CA11 associated with stomach cancer [10]. In many of these cases the Brichos domain is found in the proprotein, and it has been suggested to impact post-translational processing by exerting a chaperone-like function, and/or by affecting proteolysis of the proprotein [10].

Mutations in the human SP-C gene (SFTPC) are linked to familial and sporadic interstitial lung disease (ILD), where some of the mutations apparently cause the protein to misfold and form intracellular aggregates $[11,12]$. All mutations but one (proSP-C ${ }^{\mathrm{P} 30 \mathrm{~L}}$ ) are found in the C-terminal (lumenal) domain of proSP-C (CTC). CTC covers proSP-C residues 59-197 and thus contains the above mentioned Brichos domain and a segment that links it to the end of the transmembrane domain (see Fig. 7). Elevated expression of a mutation causing the deletion of exon 4 from proSP-C (proSP-C ${ }^{\Delta \mathrm{Exon} 4}$ ), leading to a 37 amino acid C-terminally shortened proprotein, resulted in lung dysmorphogenesis in transgenic mice and ER stress in transfected cells $[13,14]$. Another mutation in the Brichos domain, resulting in the exchange of glutamine for leucine at position 188 in the proprotein (proSP-C ${ }^{\mathrm{L} 188 \mathrm{Q}}$ ), was associated with dominantly inherited ILD in two distinct kindreds, in which affected members displayed type II cell ultrastructural abnormalities including cytosolic electron dense inclusions [15, 16]. Expression of the Brichos mutants proSP-C ${ }^{\triangle \mathrm{Exon} 4}$ or proSP-C ${ }^{\mathrm{L} 188 \mathrm{Q}}$ in lung-derived A549 cells or human embryonic kidney (HEK)293 cells resulted in increased formation of insoluble aggregates leading to apoptosis [17]. In contrast, two other mutations, proSP-C $\mathrm{C}^{\mathrm{I} 3 \mathrm{~T}}$ and proSP-C $\mathrm{C}^{\mathrm{E} 66 \mathrm{~K}}$, localised in a region between the Brichos domain and the transmembrane domain were associated with altered intracellular trafficking but not aggregation $[18,19]$.

Protein folding is a complex process further complicated by the crowded intracellular milieu. The importance of molecular chaperones, such as heat shock proteins, in the folding process is well known and has been extensively studied $[20,21]$. In addition to chaperones, a number of proteins use part of their pro-sequence as a scaffold during folding. The importance of pro-sequence-assisted folding has been established for several proteins, for example serine proteases [22] and human nerve growth factor [23]. A recent study from our group showed that recombinant CTC binds to unfolded SP-C, but not to $\alpha$-helical SP-C [24]. These findings, together with the phenotypes associated with mutations in proSP-C, led us to investigate the hypothesis that CTC promotes stability during biosynthesis of proSP-C by preventing misfolding and aggregation of the polyVal transmembrane domain.

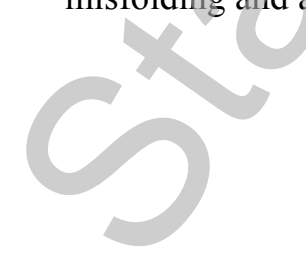




\section{EXPERIMENTAL PROCEDURES}

\section{Analysis of aggregated and soluble proSP-C in HEK293 cells}

The generation and culture of HEK293 cell lines stably expressing human wild type proSP-C, proSP$\mathrm{C}^{\mathrm{L} 188 \mathrm{Q}}$ and proSP-C ${ }^{\mathrm{AExon} 4}$ were previously described $[24,25]$; proSP-C $\mathrm{C}^{\mathrm{173T}}$ was constructed in a similar manner. A construct encoding the signal peptide from proSP-B, CTC, and the ER retention signal KDEL (CTC-KDEL) was cloned into pcDNA3.1 (InVitrogen) and constructs encoding proSP-C, proSP-C $\mathrm{C}^{\mathrm{L} 188 \mathrm{Q}}$, proSP-C(Leu), or proSP-C(Leu) ${ }^{\text {L188Q }}$ (Fig.1) were cloned into pIRES2-EGFP (BD Bioscience). Addition of a KDEL tag (which is not found in proSP-C) does not alter the effect of CTC on wild-type proSP-C, i.e. CTC does not interact with wild-type proSP-C (see Fig. 3) and CTC expression is not altered by inclusion of the KDEL tag as observed by pulse chase experiments (data not shown). A C-terminal hemagglutinin (HA) tag (YPYDVPDYA) was added to all full-length constructs used in transient transfection experiments. Cells were cultured until $70 \%$ confluency and thereafter removed from the dish and replated at 3.5-5 x $10^{5}$ cells/well of a poly-D-Lysine coated 6-well plate. Twenty-four hours later, the cells were transfected with $4 \mu$ Lipofectamine 2000 (InVitrogen): $1 \mu \mathrm{g}$ DNA (full-length constructs) or with $3 \mu 1$ Lipofectamine 2000:0.25 $\mu \mathrm{g}$ DNA (CTC-KDEL). After another 24 hours of growth, the cells were washed with PBS and harvested. Untransfected, control HEK293 cells were grown for 48 hours before harvesting.

For analysis of aggregated proteins the cell pellets were dissolved in $50 \mathrm{mM}$ Tris with $1 \%$ SDS (w/v) and $2 \mathrm{mM} \mathrm{MgCl} 2$. PEFA-block $(1 \mathrm{mM})$ was added and the pellets were sonicated for 5 minutes. Benzonase (15U, a genetically engineered DNA and RNA endonuclease from Serratia marcescens) was added and the samples were kept at room temperature for 20 min followed by centrifugation at $16000 \mathrm{xg}$ at $4{ }^{\circ} \mathrm{C}$ for 45 minutes. The supernatants were transferred to new tubes and $\beta$-mercaptoethanol $(2 \%)$ was added. Next, formic acid with $1 \%(\mathrm{w} / \mathrm{v})$ SDS was used to dissolve the remaining pellets and the samples were then lyophilised. The lyophilised samples were redissolved in $11 \%$ glycerol yielding a final SDS concentration of $1 \%$, and $B$-mercaptoethanol $(2 \%)$ was then added. All samples were heated at $100^{\circ} \mathrm{C}$ for 4 minutes prior to separation by electrophoresis on $10-16 \%$ tricine gels followed by electrophoretic transfer to polyvinylidene difluoride membranes (Pall Corporation). After blocking with 5\% non-fat dry milk, the membranes were probed with rabbit polyclonal antibodies directed against the N-terminal [26] or the C-terminal domain of proSP-C [24]. Enhanced chemiluminescence (Millipore) was used to detect antibody binding.

For analysis of soluble proteins, cells were harvested directly into Laemmli sample buffer (BioRad) and immediately sonicated. Prior to loading, $B$-mercaptoethanol $(1 \%)$ was added and each sample was heated at $100^{\circ} \mathrm{C}$ for 4 minutes. Proteins were separated by electrophoresis on $10-20 \%$ tricine gels (InVitrogen) followed by electrophoretic transfer to $0.1 \mathrm{~mm}$ nitrocellulose membranes (ISC BioExpress). After blocking with $5 \%$ non-fat dry milk, the membranes were probed with rabbit polyclonal antibodies directed against the N-terminal propeptide of proSP-C, CTC, mature SP-C [27], green fluorescent protein (Molecular Probes), HA tag (Santa Cruz Biotechnologies) or mouse monoclonal actin antibody (Seven Hills Bioreagents). Antigen-antibody complexes were visualized using the SuperSignal West Pico detection system (Pierce). Stripping of nitrocellulose membrane was performed using the Restore Western Blot Stripping Buffer (Pierce).

\section{Congo red fluorescence}

HEK293 cells stably expressing human wild type proSP-C, proSP-C $\mathrm{C}^{\mathrm{L} 188 \mathrm{Q}}$, proSP-C $\mathrm{C}^{\Delta \mathrm{Exon} 4}$, or proSP-C ${ }^{\mathrm{I} 73 \mathrm{~T}}$ were cultured until $70 \%$ confluency and thereafter removed from the dish and replated on culture slides at $1.5 \times 10^{5}$ cells/slide. Cells transiently transfected with proSP-C(Leu $)^{\mathrm{L} 188 \mathrm{Q}}$ or proSP-C $\mathrm{C}^{\mathrm{L} 188 \mathrm{Q}}$ as described above were replated on culture slides at $3.5 \times 10^{5}$ cells/slide $24 \mathrm{~h}$ after transfection. After 24 or 48 hours the cells were washed three times with PBS, fixed with $4 \%$ paraformaldehyde, and permeabilized with $0.5 \%$ Triton $\mathrm{X}-100$. The cells were then incubated in $80 \%$ ethanol with saturated sodium chloride and $1 \%$ sodium hydroxide for 10 minutes, followed by 10 minutes in the same solution with $0.02 \%$ Congo red. 
Finally the slides were rinsed in ethanol for 5 seconds before dehydration and mounting. The cells were analyzed and photographed using a Zeiss LSM 510 Meta confocal microscope. Excitation wavelength was $543 \mathrm{~nm}$ and a normal light image was used as background to show the cell surface structure. For each low magnification spot suspected to represent intracellular protein aggregates, a Z-stack tool for visualization of different layers at higher magnification was used to differentiate it from condensed nuclear material. The arrows in Figure 2 mark spots concluded to represent protein aggregates by this procedure.

\section{Pulse-chase and immunoprecipitation experiments}

HEK293 cells were incubated for 30 min in methionine- and cysteine-free Dulbecco's modified Eagle's medium (Invitrogen) supplemented with 10\% dialyzed fetal bovine serum. Cells were then pulse-labeled with $0.5 \mathrm{mCi} / \mathrm{ml}^{35}\{\mathrm{~S}\}$-methionine/cysteine (MP Biomedicals, Irvine, CA) for $30 \mathrm{~min}$ and chased in complete medium (fresh DMEM containing unlabeled methionine/cystine ( $95 \mathrm{mM})$ ) for 1, 2, and $4 \mathrm{hrs}$. Immunoprecipitations were performed from equivalent amounts of cell lysates with anti pro-SP-C and protein $\mathrm{G}$ beads (Zymed, InVitrogen) at $4^{\circ} \mathrm{C}$ overnight on a rotating wheel. Captured immunocomplexes were washed six times, and then incubated at $100^{\circ} \mathrm{C}$ for 4 min with electrophoresis sample buffer. Immunoprecipitated proteins were analyzed by SDS-PAGE under reducing electrophoretic conditions followed by autoradiography.

\section{Co-precipitation experiments}

$2.5 \times 10^{6}$ stably transfected HEK293 cells expressing wild-type proSP-C or proSP-C $\mathrm{C}^{\mathrm{L} 188 \mathrm{Q}}$ were transiently transfected with 10 ug of pCDNA3.1+ (Invitrogen) or pCDNA3.1+:CTC-KDEL and 18 ul Lipofectamine 2000 (Invitrogen) in lysine-coated 6-well plates. At $48 \mathrm{~h}$, cells were washed twice with $1 \mathrm{x}$ PBS and harvested in 500 ul lysis buffer (20 mM HEPES, pH 7.6, $125 \mathrm{mM} \mathrm{NaCl}, 10 \%$ glycerol, $1 \%$ Triton X-100, $1 \mathrm{mM}$ EDTA, $1 \mathrm{mM}$ EGTA, $1 \mathrm{mM}$ DTT, and Sigma \#P8340 protease inhibitor cocktail). After $2 \mathrm{~h}$ rotation at $4^{\circ} \mathrm{C}$, cells were briefly sonicated and centrifuged at $10,000 \mathrm{rpm}, 10 \mathrm{~min}, 4^{\circ} \mathrm{C}$. Supernatants were incubated with or without $5 \mathrm{ul}$ of N-terminal proSP-C antibody overnight at $4^{\circ} \mathrm{C}$. Samples were rotated with $50 \mathrm{ul}$ of rec-Protein A-proSepharose 4B (Zymed Laboratories) at room temperature for $2 \mathrm{~h}$. Four $1 \mathrm{ml}$ washes (20 mM HEPES, pH7.6, $500 \mathrm{mM} \mathrm{NaCl}$, and $1 \%$ Triton X-100) were followed by elution with $50 \mathrm{ul}$ of reducing Laemmli buffer. Eluates were heated at $100^{\circ} \mathrm{C}$ for $4 \mathrm{~min}$ and subjected to Western blot analysis with C-terminal proSPC antibody using the Genscript One-Step IP-Western Kit (GenScript Corporation).

\section{CTC expression and purification}

CTC was expressed and purified as described recently [24]. Briefly, a fragment covering residues 59-197 of human pro-SP-C (Fig. 1) was expressed as a fusion protein with thioredoxin- His $6^{-}$and S-tags in E.coli. The protein was purified using immobilised metal affinity and ion exchange chromatography. Thrombin was used for removal of thioredoxin- and $\mathrm{His}_{6}$-tags. The protein purity and molecular mass were checked with SDS-PAGE and matrix-assisted laser desorption ionisation (MALDI) mass spectrometry, respectively. CTC was found to be $>95 \%$ pure and to have the expected mass.

\section{SP-C amyloid fibril formation}

Curosurf and SP-C33 surfactant were provided by Chiesi Farmaceutici, Parma, Italy. Curosurf is prepared from porcine lungs and contains $98 \%(\mathrm{w} / \mathrm{w})$ phospholipids and 1-2 \% (w/w) of SP-B and SP-C [28]. SPC33 surfactant is fully synthetic and contains $98 \%(w / w)$ phospholipids and $2 \%(w / w)$ of an SP-C analogue in which the polyVal sequence of native SP-C is replaced by a polyLeu stretch [29]. Curosurf or $\mathrm{SP}-\mathrm{C} 33$ surfactant were diluted to $5 \mathrm{mg} / \mathrm{ml}$ in $150 \mathrm{mM}$ sodium chloride with $0.02 \%$ sodium azide to a final volume of $4.5 \mathrm{ml}$ and incubated at $22^{\circ} \mathrm{C}$ with shaking, with or without $7.5 \mu \mathrm{M}$ CTC. This corresponds to a CTC:SP-C/SP-C33 molar ratio of 0.5-1. After 0, 7 and 14 days, suspensions were 
centrifuged at $100,000 \mathrm{xg}$ for $30 \mathrm{~min}$ at $22^{\circ} \mathrm{C}$, the supernatants removed and the pellets suspended in $1 \%$ $(\mathrm{w} / \mathrm{v})$ SDS. This procedure was repeated four times. The final, SDS-insoluble pellets were suspended in $200 \mu \mathrm{l}$ of water and bath-sonicated. Aliquots of $2 \mu 1$ were removed for electron microscopy as described below.

\section{Transmission electron microscopy}

Aliquots of $2 \mu 1$ of the suspended SDS-insoluble pellets were adsorbed for 1 min on 200-mesh copper grids and stained with $2 \%$ uranyl acetate for $30 \mathrm{~s}$ before being examined and photographed using a Hitachi $\mathrm{H} 7100$ microscope operated at 75 or $100 \mathrm{kV}$.

\section{MALDI mass spectrometry}

SP-C33 (IPSSPVHLKRLKLLLLLLLLILLLILGALLMGL) and a synthetic non-helical SP-C analogue [30] (LRIPSSPVNLKRLLVVVVVVVLVVVVIVGALLMGL) were dissolved to a concentration of 4.5 $\mathrm{mM}$ in ethanol or formic acid, respectively, and diluted 10 times in $30 \%$ acetonitrile, $0.1 \%$ trifluoroacetic acid (TFA). CTC in $20 \mathrm{mM}$ sodium phosphate buffer $\mathrm{pH} 7.4,30 \mathrm{mM}$ sodium chloride was diluted 10 times to a concentration of $120 \mu \mathrm{M}$ in $30 \%$ acetonitrile, $0.1 \%$ TFA. CTC and the individual peptides were mixed at a 1:1 molar ratio and further diluted 100 times in $30 \%$ acetonitrile, $0.1 \%$ TFA. Aliquots of $0.5 \mu 1$ of the CTC/peptide mixtures were spotted onto a pre-prepared thin layer of $30 \mathrm{mg} / \mathrm{ml}$ sinapinnic acid (Bruker Daltonics, Billerica, MA) in acetone and covered with another $0.5 \mu 1$ of $30 \mathrm{mg} / \mathrm{ml}$ sinapinnic acid in $50 \%$ acetonitrile, $0.1 \%$ TFA. MALDI mass spectrometry was performed using a Bruker Autoflex (Bruker Daltonics, Billerica, MA) in linear mode. 


\section{RESULTS}

\section{Aggregation behaviour of proSP-C ${ }^{\mathrm{L} 188 \mathrm{Q}}$, proSP-C $\mathrm{C}^{\mathrm{AExon4}}$, and proSP-C $\mathrm{C}^{173 \mathrm{~T}}$ in $\mathrm{HEK293}$ cells}

To study effects of the L188Q, $\triangle$ Exon4, and I73T mutations, respectively, on proSP-C aggregation, HEK293 cells stably transfected with wild type proSP-C or mutant proSP-C were used. Congo red staining, a classical method for detection of amyloid [31], revealed red spots in the cells expressing proSP-C ${ }^{\mathrm{L} 188 \mathrm{Q}}$ or proSP-C ${ }^{\Delta \mathrm{Exon} 4}$ (Fig. 2A). In the L188Q cells the spots were brighter than in $\triangle$ Exon4 cells. Cells expressing proSP-C ${ }^{\mathrm{I73T}}$ showed $<10 \%$ red spots compared to proSP-C ${ }^{\mathrm{L} 188 \mathrm{Q}}$ and proSP-C ${ }^{\triangle \mathrm{Exon} 4}$ (data not shown), and in cells expressing wild-type proSP-C no Congo red spots could be found (Fig. 2A). To further examine the effect of the mutations, SDS-insoluble, but formic acid soluble protein (a feature typical of amyloid [32]) from HEK293 cells expressing either wild type or mutant proSP-C were analyzed using Western blotting (Fig. 2B). In the mutant proSP-C cells large ( $>210 \mathrm{kDa})$ immunoreactive aggregates were found, which were not present in the cells expressing wild type proSP-C. The relative amounts of these aggregates were L188Q $>\Delta$ Exon $4>$ I73T (Fig. 2B). Together these findings indicate that the L188Q mutation promotes aggregation into Congo red positive deposits in HEK293 cells, and the same phenomenon, although somewhat less pronounced, is seen with the $\Delta$ Exon 4 mutation. The I73T mutation does not produce Congo red positive inclusions in HEK293 cells, and gives rise to smaller amounts of SDS-insoluble protein. Further experiments were performed using cells expressing proSP$\mathrm{C}^{\mathrm{L} 188 \mathrm{Q}}$, since these showed the clearest differences compared to wild type cells.

\section{ProSP-C ${ }^{\text {L188Q }}$ aggregation after transfection with CTC}

HEK293 cells stably expressing proSP-C $C^{\text {L188Q }}$ were transiently transfected with CTC-KDEL (Fig. 1) and analysed for Congo red inclusions and amounts of aggregated and soluble proSP-C ${ }^{\mathrm{L} 188 \mathrm{C}}$. An increase in SDS-soluble proSP-C ${ }^{\mathrm{L} 188 \mathrm{Q}}$ levels was observed (data not shown), and was more pronounced than previously found after transfection with CTC lacking KDEL [24], as expected since the KDEL tag holds $\mathrm{CTC}$ in the ER. More importantly, transfection of CTC inhibited formation of Congo red positive inclusions (Fig. 3A) and SDS-insoluble/formic acid soluble aggregates (Fig. 3B). Moreover, coprecipitation experiments showed that CTC binds to proSP-C $\mathrm{C}^{188 \mathrm{Q}}$ (in the absence of any cross-linking reagent), while only marginally binding to wild-type proSP-C (Fig. 3C). Pulse-chase experiments showed a pronounced increase in proSP-C $\mathrm{C}^{\mathrm{L} 188 \mathrm{Q}}$ half-life upon CTC transfection, and confirmed that CTC forms a complex with proSP-C $C^{\mathrm{L} 188 \mathrm{Q}}$ (Fig. 3D). Formation of CTC/proSP-C $\mathrm{C}^{\mathrm{L} 188 \mathrm{Q}}$ complex also increased the stability of CTC (Fig. 3D). These results indicate that CTC added in trans exerts effects in the ER, forms a complex with proSP-C ${ }^{\mathrm{L} 188 \mathrm{Q}}$, and prevents aggregation of proSP-C $\mathrm{C}^{\mathrm{L} 188 \mathrm{Q}}$.

Recombinant $\mathrm{CTC}^{\mathrm{L} 188 \mathrm{Q}}$ does not aggregate in vitro [24], which suggests that the proSP-C ${ }^{\mathrm{L} 188 \mathrm{Q}}$ inclusions seen in HEK293 cells (Fig. 2) may be mediated by aggregation of region(s) outside CTC. Furthermore, recombinant CTC $C^{\mathrm{L} 1880}$, in contrast to wildtype CTC, does not bind to non-helical SP-C [24]. It is thus possible that the polyVal segment mediates proSP-C ${ }^{\mathrm{L} 188 \mathrm{Q}}$ aggregation, and that in the CTC/proSP-C ${ }^{188 Q}$ complex, CTC binds to the polyVal region of proSP-C. In order to test these hypotheses we next studied the effects of CTC on SP-C amyloid fibril formation (a process that requires unfolding of its $\alpha$-helix [8]), CTC binding to non-helical SP-C, and the effects of replacing the polyVal region of proSP-C ${ }^{\mathrm{L} 188 \mathrm{Q}}$ with a polyLeu sequence.

\section{Effects of recombinant CTC on SP-C amyloid fibril formation and CTC binding to SP-C}

In order to study SP-C in its natural phospholipid environment, a lung surfactant preparation containing phospholipids, SP-C and SP-B, was incubated at room temperature for 7 and 14 days and thereafter subjected to an SDS extraction procedure previously used for isolation of fibrillar amyloid $\beta$-peptide from brain tissue of Alzheimer's disease patients [32], or SP-C fibrils from PAP patients [9]. At time 0 no aggregates were observed, but after 7 or 14 days SP-C had aggregated into amyloid-like fibrils, as seen by electron microscopy (Fig. 4A and B). MALDI mass spectrometry confirmed the presence of SP-C in the aggregates (data not shown). In the presence of CTC at a molar ratio of about $0.5-1$ versus SP-C, SP-C fibril formation was fully prevented after 7 days (Fig. 4C) and after 14 days incubation (not shown). A 
surfactant preparation containing phospholipids and an SP-C analogue with a polyLeu stretch replacing the polyVal part [33], was incubated in the same manner as described above. In this case no amyloid fibrils were observed by electron microscopy (Fig. 4D), and the presence of CTC had no effect (not shown). This is relevant with regard to the experiments with polyLeu substituted proSP-C described below.

MALDI mass spectrometry (Fig. 5) show that recombinant CTC binds to synthetic SP-C which is non-helical [30], but not to a polyLeu analogue which is helical [34] under all conditions analysed. Complexes between CTC and one, two, or three SP-C molecules were observed. Recombinant CTC on its own forms dimers and trimers (Fig. 5A) [35], but binding to non-helical SP-C seems to reduce CTC oligomerisation (compare the amounts of CTC dimers and trimers in Figs. 5A and B)

These results show that in the presence of phospholipids SP-C, but not a polyVal $\rightarrow$ polyLeu analogue, can assemble into amyloid fibrils, that fibril formation is prevented by the presence of CTC, and that recombinant CTC binds to non-helical SP-C, as previously shown for the poly-valine peptide $\mathrm{K}_{2} \mathrm{~V}_{7} \mathrm{~K}_{2}$ [24].

\section{Effects on proSP-C ${ }^{\mathrm{L} 188 \mathrm{Q}}$ aggregation by modulation of its transmembrane amino acid sequence}

The data above imply that the polyVal region of (pro)SP-C is unstable and can convert from $\alpha$-helix to $\beta$ sheet aggregates, and that CTC prevents it from aggregating. We therefore analysed how replacement of polyVal with a less aggregation-prone polyLeu sequence (cf. Fig. 4) affects aggregation of proSP-C $\mathrm{C}^{\mathrm{L} 188 \mathrm{Q}}$. Transient expression of proSP-C(Leu) in HEK293 cells resulted in processing of the proprotein to the mature peptide, an event that occurs in the lysosome. The level of proprotein and mature peptide was similar to wild-type proSP-C (Fig. 6A, lanes 1 and 2) and the rate of processing (estimated from pulse chase experiments, not shown) was likewise similar for the two proproteins. Thus substitution of the polyVal region of proSP-C with polyLeu (Fig. 1) did not affect expression, ER export or processing of proSP-C. To determine if polyLeu substitution would promote ER export and processing of mutant proSP-C, the L188Q mutation was introduced into proSP-C(Leu) to generate proSP-C(Leu) ${ }^{\mathrm{L} 188 \mathrm{Q}}$. Mutant proSP-C accumulated in HEK cells (Fig. 6A, lanes 3 and 4) compared to cells expressing wild-type proSP-C (Fig. 6A, lanes 1 and 2) regardless of the presence (Fig. 6A, lane 4) or absence (Fig. 6A, lane 3) of the polyLeu substitution. The mutant proprotein was not processed to mature peptide consistent with retention in the ER (Fig. 6A, upper panel). Importantly, upon transient transfection of proSP-C $\mathrm{C}^{\mathrm{L} 188 \mathrm{Q}}$ or proSP-C(Leu ${ }^{\mathrm{L} 188 \mathrm{Q}}$ into HEK cells, only the former resulted in Congo red positive inclusions (not shown) and formation of large SDS-insoluble, formic acid soluble proSP-C aggregates (Fig. 6B). The Congo red positive spots obtained after transient expression of proSP-C $\mathrm{C}^{\mathrm{L} 188 \mathrm{Q}}$ were not as bright as those found after stable expression (not shown). The presence of SDS-insoluble monomeric proSP-C(Leu ${ }^{\text {L188Q }}$ (Fig. 6B) is compatible with aggregation without formation of amyloid-like deposits. In line with decreased levels of aggregated protein, proSP-C(Leu) ${ }^{\mathrm{L} 188 \mathrm{Q}}$ transfection resulted in increased levels of SDS-soluble protein relative to the polyVal proSP-C ${ }^{\text {L188Q }}$ (Fig. 6A, lanes 3 and 4). However, the half-lifes of soluble proSP$\mathrm{C}^{\mathrm{L} 188 \mathrm{Q}}$ and proSP-C(Leu) ${ }^{\mathrm{L} 188 \mathrm{Q}}$ are similar, as judged by pulse-chase experiments (data not shown).

These experiments indicate that formation of Congo red positive inclusions and large SDS-insoluble aggregates of proSP-C carrying the mutation L188Q requires a polyVal transmembrane region. ProSP$\mathrm{C}(\mathrm{Leu})^{\mathrm{L} 188 \mathrm{Q}}$, like proSP-C $\mathrm{C}^{\mathrm{L} 188 \mathrm{Q}}$, was not processed to a $4 \mathrm{kDa}$ mature peptide (Fig. $6 \mathrm{~A}$ ), and both proteins were degraded with similar kinetics. This indicates that polyVal $\rightarrow$ polyLeu substitution of the transmembrane domain prevents aggregation, but does not allow proSP-C(Leu $)^{\mathrm{L} 188 \mathrm{Q}}$ to escape ER quality control.

\section{DISCUSSION}

This study shows that two proSP-C mutations associated with familial forms of ILD in humans, L188Q and $\triangle$ Exon4, give rise to intracellular Congo red positive inclusions when expressed in HEK293 cells. The L188Q mutation appears to give rise to such inclusions more efficiently than the $\Delta$ Exon 4 mutation. 
The data also suggest that the L188Q mutation gives rise to formation of amyloid-like inclusions by an indirect mechanism, since it requires the presence of a polyVal transmembrane segment in proSP-C. These data are of interest as regards ILD pathogenesis and anti-amyloid mechanisms.

The C-terminal part of proSP-C contains a recently discovered Brichos domain. Sequence alignments indicate that the Brichos domain of proSP-C covers residues 94-197 and this is supported by limited proteolysis experiments [35]. One of several suggested functions of the Brichos domain is a chaperonelike role [10], but this has so far not been shown experimentally. Mutations in the SFTPC gene that are associated with ILD are found in three different regions of proSP-C. First, a majority of the mutations are found within the Brichos domain and these appear to lead to a more severe phenotype, with decreased or no mature SP-C and formation of cytotoxic protein aggregates [11]. Second, mutations localised in the region between the Brichos domain and the transmembrane domain are mainly associated with altered intracellular trafficking [18]. Third, one mutation has been found in the mature peptide and the phenotype associated with it has not been well characterised, but ER retention has been suggested [11]. HEK293 cells that stably express proSP-C ${ }^{\mathrm{L} 188 \mathrm{Q}}$ and proSP-C $\mathrm{C}^{\Delta \mathrm{Exon} 4}$ (located in the Brichos domain), but not proSP$\mathrm{C}^{\mathrm{I} 73 \mathrm{~T}}$ (located between the Brichos domain and the transmembrane domain) show Congo red positive depositions and abundant SDS-insoluble aggregates (Fig. 2). This supports the hypothesis that different mechanisms are involved in pathogenesis of ILD linked to proSP-C mutations.

After transfection of HEK293 cells stably expressing proSP-C ${ }^{\text {L188 }}$ with a CTC-KDEL construct, Congo red positive inclusions and SDS-insoluble/formic acid soluble aggregates are reduced, a bimolecular complex is formed, and an increased half-life of the SDS-soluble form of proSP-C ${ }^{\mathrm{L} 188 \mathrm{Q}}$, as well as CTC, is seen (Fig. 3). This shows that CTC can prevent aggregation of mutant proSP-C in the ER and that CTC can function in trans, consistent with a chaperone function. Moreover, SP-C can aggregate into amyloid fibrils but this is prevented by CTC (Fig. 4). CTC binds to mono-and oligomeric, non-helical SP-C in solution (Fig. 5), and in the presence of phospholipids [24], but recombinant CTC $^{\mathrm{L} 188 \mathrm{Q}}$ does not bind non-helical SP-C [24]. These data imply that CTC binds to unfolded SP-C and that a function of CTC may be to prevent unfolded polyVal segments of proSP-C from aggregating into amyloid-like deposits during biosynthesis (Fig. 7). They further suggest that loss of this chaperone function by the ILD-associated mutation L188Q may contribute to formation of amyloid-like intracellular inclusions.

Mechanisms that prevent protein aggregation reduce ER stress and promote cell survival. Examples of intramolecular features include proline residues localised N-terminally of transmembrane helices, which promote helix formation by disfavouring alternative intermolecular hydrogen bonding [36], localisation of charged residues in edge $\beta$-strands to prevent intermolecular $\beta$-sheet formation [37] and structural "gatekeepers" (for example charged side chains) that prevent unfavourable interactions by interrupting contiguous stretches of hydrophobic residues [38]. In addition to these mechanisms, molecular chaperones afford an intermolecular mechanism for prevention of aggregation [20]. Molecular chaperones include several families of proteins that prevent misfolding by interacting with folding intermediates, thereby preventing aggregation and allowing the proteins to fold correctly. Chaperones have little apparent substrate specificity and are as a rule promiscuous, recognising common features of unfolded proteins like exposed hydrophobic patches. The extracellular protein clusterin, also known as apolipoprotein J, can prevent amyloid formation by binding to prefibrillar species, and it may thus confer protection to extracellular amyloid formation $[39,40]$.

SP-C, by design, has a high tendency to misfold and aggregate into amyloid fibrils, mediated by its polyVal domain [41]. The polyVal domain constitutes a regular $\alpha$-helix in native SP-C, but is predicted to form a $\beta$-strand by algorithms that are based on information largely from water soluble proteins [7]. The efficiency of folding of transmembrane helices correlates with their helical propensity in aqueous solution; poly-Leu segments are folded into compact, possibly helical, structure already in the translocon while poly-Val has a more extended conformation [42]. SP-C is highly inefficient in forming helical structure, in contrast to polyVal $\rightarrow$ polyLeu substituted variants $[8,30,33,34]$. It is therefore likely that formation of the proSP-C polyVal transmembrane helix is comparatively inefficient [24]. In support of this suggestion, the L188Q mutation yields different effects on aggregation when introduced in proSP-C compared to in polyLeu substituted proSP-C(Leu) (Fig. 6). In the latter case no Congo red positive 
inclusions or large SDS-insoluble aggregates are observed. This is an intriguing observation as it indicates that intracellular aggregation into amyloid-like deposits of proSP-C $C^{\mathrm{L} 188 \mathrm{Q}}$ is mediated by the polyVal segment localised about 140 residues N-terminally of the mutation.

The concept of pro-sequence assisted protein folding was first demonstrated for serine proteases, but has been found in a number of proteins including proinsulin and certain growth factors [43]. These prosequences are highly substrate specific and in many cases act like true catalysts for folding. The segments vary in length ranging from 10 residues up to 800 and are typically cleaved off after folding has occurred [43]. Covalent linkage of the pro-sequences to the mature part is not essential for correct folding; some pro-sequences function in trans when added as separate polypeptide chains [44]. ProSP-C appears to represent an example of prosequence assisted folding, and it remains to be clarified whether it works intra- and/or intermolecularly. To elucidate if CTC can catalyse formation of the proSP-C transmembrane helix or if it only prevents aggregation of non-folded variants, likewise warrants further studies.

The issue of interactions between wild type and mutant protein is of interest in relation to amyloid disease. Tissue deposits containing fibrils from patients with systemic lysozyme amyloidosis contain only mutant lysozyme, even though all patients analysed have been heterozygotic, with wild-type as well as amyloidogenic mutants in serum [45]. In contrast, proSP-C mutations, at least those in the Brichos domain, give rise to a dominant-negative phenotype as all mutations so far characterised are found on only one allele and are frequently associated with reduced levels of mature SP-C in the alveoli, consistent with intracellular trapping of wild type protein [46]. The indirect mechanism now proposed for amyloid formation by proSP-C Brichos mutations is compatible with non-mutant protein being incorporated into fibrils, as the sites of mutation and aggregation are suggested to be separate.

In conclusion, this work suggests that the C-terminal, ER-lumenal region of proSP-C, in particular the Brichos domain has chaperone-like properties that prevent the transmembrane part of proSP-C from aggregating before it has attained helical conformation. Such an inbuilt protective mechanism for prevention of aggregation and amyloid fibril formation has not been described previously. Whether this CTC function is required because of the apparently unique polyVal region of proSP-C, or if similar cases exist, remains to be investigated. The data presented here raise questions whether the effects of CTC are applicable to amyloidogenic proteins other than proSP-C, and whether they represent a function also present in other proteins containing a Brichos domain.

This work was supported by the Swedish Research Council (project 10371), the Swedish Research Council for Environment, Agricultural Sciences and Spatial Planning, and the National Institutes of Health (P01-HL61646).

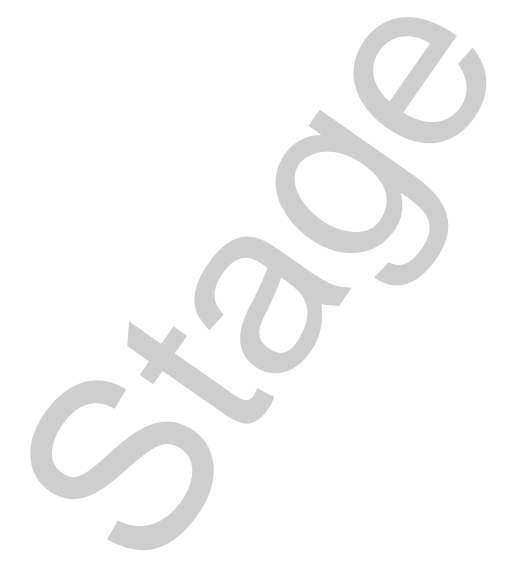




\section{REFERENCES}

1 Beers, M. F. and Lomax, C. (1995) Synthesis and processing of hydrophobic surfactant protein $C$ by isolated rat type II cells. Am J Physiol. 269, L744-753

2 Conkright, J. J., Bridges, J. P., Na, C. L., Voorhout, W. F., Trapnell, B., Glasser, S. W. and Weaver, T. E. (2001) Secretion of surfactant protein C, an integral membrane protein, requires the N-terminal propeptide. J Biol Chem. 276, 14658-14664

3 Li, J., Hosia, W., Hamvas, A., Thyberg, J., Jornvall, H., Weaver, T. E. and Johansson, J. (2004) The N-terminal propeptide of lung surfactant protein $\mathrm{C}$ is necessary for biosynthesis and prevents unfolding of a metastable $\alpha$-helix. J. Mol. Biol. 338, 857-862

4 Glasser, S. W., Korfhagen, T. R., Wert, S. E., Bruno, M. D., McWilliams, K. M., Vorbroker, D. K. and Whitsett, J. A. (1991) Genetic element from human surfactant protein SP-C gene confers bronchiolar-alveolar cell specificity in transgenic mice. Am J Physiol. 261, L349-356

5 Russo, S. J., Wang, W., Lomax, C. A. and Beers, M. F. (1999) Structural requirements for intracellular targeting of SP-C proprotein. Am J Physiol. 277, L1034-1044

6 Whitsett, J. A. and Weaver, T. E. (2002) Hydrophobic surfactant proteins in lung function and disease. N Engl J Med. 347, 2141-2148

7 Kallberg, Y., Gustafsson, M., Persson, B., Thyberg, J. and Johansson, J. (2001) Prediction of amyloid fibril-forming proteins. J Biol Chem. 276, 12945-12950

8 Szyperski, T., Vandenbussche, G., Curstedt, T., Ruysschaert, J. M., Wuthrich, K. and Johansson, J. (1998) Pulmonary surfactant-associated polypeptide C in a mixed organic solvent transforms from a monomeric $\alpha$-helical state into insoluble $\beta$-sheet aggregates. Protein Sci. 7, 2533-2540

9 Gustafsson, M., Thyberg, J., Naslund, J., Eliasson, E. and Johansson, J. (1999) Amyloid fibril formation by pulmonary surfactant protein C. FEBS Lett. 464, 138-142

10 Sanchez-Pulido, L., Devos, D. and Valencia, A. (2002) BRICHOS: a conserved domain in proteins associated with dementia, respiratory distress and cancer. Trends Biochem Sci. 27, 329-332

11 Beers, M. F. and Mulugeta, S. (2005) Surfactant protein C biosynthesis and its emerging role in conformational lung disease. Annu Rev Physiol. 67, 663-696

12 Nogee, L. M. (2004) Alterations in SP-B and SP-C expression in neonatal lung disease. Annu Rev Physiol. 66, 601-623

13 Bridges, J. P., Wert, S. E., Nogee, L. M. and Weaver, T. E. (2003) Expression of a human surfactant protein $\mathrm{C}$ mutation associated with interstitial lung disease disrupts lung development in transgenic mice. J Biol Chem. 278, 52739-52746

14 Wang, W. J., Mulugeta, S., Russo, S. J. and Beers, M. F. (2003) Deletion of exon 4 from human surfactant protein $\mathrm{C}$ results in aggresome formation and generation of a dominant negative. J Cell Sci. 116, 683-692

15 Thomas, A. Q., Lane, K., Phillips, J., 3rd, Prince, M., Markin, C., Speer, M., Schwartz, D. A., Gaddipati, R., Marney, A., Johnson, J., Roberts, R., Haines, J., Stahlman, M. and Loyd, J. E. (2002) Heterozygosity for a surfactant protein $C$ gene mutation associated with usual interstitial pneumonitis and cellular nonspecific interstitial pneumonitis in one kindred. Am J Respir Crit Care Med. 165, 1322-1328

16 Chibbar, R., Shih, F., Baga, M., Torlakovic, E., Ramlall, K., Skomro, R., Cockcroft, D. W. and Lemire, E. G. (2004) Nonspecific interstitial pneumonia and usual interstitial pneumonia 
with mutation in surfactant protein $\mathrm{C}$ in familial pulmonary fibrosis. Mod Pathol. 17, 973980

17 Mulugeta, S., Maguire, J. A., Newitt, J. L., Russo, S. J., Kotorashvili, A. and Beers, M. F. (2007) Misfolded BRICHOS SP-C mutant proteins induce apoptosis via caspase-4- and cytochrome c-related mechanisms. Am J Physiol Lung Cell Mol Physiol. 293, L720-729

18 Brasch, F., Griese, M., Tredano, M., Johnen, G., Ochs, M., Rieger, C., Mulugeta, S., Muller, K. M., Bahuau, M. and Beers, M. F. (2004) Interstitial lung disease in a baby with a de novo mutation in the SFTPC gene. Eur Respir J. 24, 30-39

19 Stevens, P. A., Pettenazzo, A., Brasch, F., Mulugeta, S., Baritussio, A., Ochs, M., Morrison, L., Russo, S. J. and Beers, M. F. (2005) Nonspecific interstitial pneumonia, alveolar proteinosis, and abnormal proprotein trafficking resulting from a spontaneous mutation in the surfactant protein C gene. Pediatr Res. 57, 89-98

20 Hartl, F. U. (1996) Molecular chaperones in cellular protein folding. Nature. 381, 571-579

$21 \mathrm{Ma}$, Y. and Hendershot, L. M. (2004) ER chaperone functions during normal and stress conditions. J Chem Neuroanat. 28, 51-65

22 Eder, J., Rheinnecker, M. and Fersht, A. R. (1993) Folding of subtilisin BPN': role of the pro-sequence. J Mol Biol. 233, 293-304

23 Rattenholl, A., Ruoppolo, M., Flagiello, A., Monti, M., Vinci, F., Marino, G., Lilie, H., Schwarz, E. and Rudolph, R. (2001) Pro-sequence assisted folding and disulfide bond formation of human nerve growth factor. J Mol Biol. 305, 523-533

24 Johansson, H., Nordling, K., Weaver, T. E. and Johansson, J. (2006) The Brichos domaincontaining C-terminal part of pro-surfactant protein $\mathrm{C}$ binds to an unfolded poly-val transmembrane segment. J Biol Chem. 281, 21032-21039

25 Bridges, J. P., Xu, Y., Na, C. L., Wong, H. R. and Weaver, T. E. (2006) Adaptation and increased susceptibility to infection associated with constitutive expression of misfolded SPC. J Cell Biol. 172, 395-407

26 Vorbroker, D. K., Profitt, S. A., Nogee, L. M. and Whitsett, J. A. (1995) Aberrant processing of surfactant protein C in hereditary SP-B deficiency. Am J Physiol. 268, L647-656

27 Ross, G. F., Ikegami, M., Steinhilber, W. and Jobe, A. H. (1999) Surfactant protein C in fetal and ventilated preterm rabbit lungs. Am J Physiol. 277, L1104-1108

28 Robertson, B., Curstedt, T., Johansson, J., Jörnvall, H. \& Kobayashi, T. (1990) Structural and functional characterization of porcine surfactant isolated by liquid-gel chromatography. In Prog Respir Res (von Wichert P., Müller, P. eds.). pp. 237-246, Karger, Basel

29 Johansson, J., Some, M., Linderholm, B. M., Almlen, A., Curstedt, T. and Robertson, B. (2003) A synthetic surfactant based on a poly-Leu SP-C analog and phospholipids: effects on tidal volumes and lung gas volumes in ventilated immature newborn rabbits. J Appl Physiol. 95, 2055-2063

30 Johansson, J., Nilsson, G., Stromberg, R., Robertson, B., Jornvall, H. and Curstedt, T. (1995) Secondary structure and biophysical activity of synthetic analogues of the pulmonary surfactant polypeptide SP-C. Biochem J. 307, 535-541

31 Westermark, G. T., Johnson, K. H. and Westermark, P. (1999) Staining methods for identification of amyloid in tissue. Methods Enzymol. 309, 3-25

32 Naslund, J., Schierhorn, A., Hellman, U., Lannfelt, L., Roses, A. D., Tjernberg, L. O., Silberring, J., Gandy, S. E., Winblad, B., Greengard, P. and et al. (1994) Relative abundance of Alzheimer A $\beta$ amyloid peptide variants in Alzheimer disease and normal aging. Proc Natl Acad Sci U S A. 91, 8378-8382 
33 Hosia, W., Johansson, J. and Griffiths, W. J. (2002) Hydrogen/deuterium exchange and aggregation of a polyvaline and a polyleucine alpha-helix investigated by matrix-assisted laser desorption ionization mass spectrometry. Mol Cell Proteomics. 1, 592-597.

34 Nilsson, G., Gustafsson, M., Vandenbussche, G., Veldhuizen, E., Griffiths, W. J., Sjovall, J., Haagsman, H. P., Ruysschaert, J. M., Robertson, B., Curstedt, T. and Johansson, J. (1998) Synthetic peptide-containing surfactants--evaluation of transmembrane versus amphipathic helices and surfactant protein C poly-valyl to poly-leucyl substitution. Eur J Biochem. 255, 116-124

35 Casals, C., Johansson, H., Saenz, A., Gustafsson, M., Alfonso, C., Nordling, K. and Johansson, J. (2008) C-terminal, endoplasmic reticulum-lumenal domain of prosurfactant protein $\mathrm{C}$ - structural features and membrane interactions. FEBS J. 275, 536-547

36 Wigley, W. C., Corboy, M. J., Cutler, T. D., Thibodeau, P. H., Oldan, J., Lee, M. G., Rizo, J., Hunt, J. F. and Thomas, P. J. (2002) A protein sequence that can encode native structure by disfavoring alternate conformations. Nat Struct Biol. 9, 381-388

37 Richardson, J. S. and Richardson, D. C. (2002) Natural beta-sheet proteins use negative design to avoid edge-to-edge aggregation. Proc Natl Acad Sci U S A. 99, 2754-2759

38 Otzen, D. E., Kristensen, O. and Oliveberg, M. (2000) Designed protein tetramer zipped together with a hydrophobic Alzheimer homology: a structural clue to amyloid assembly. Proc Natl Acad Sci U S A. 97, 9907-9912

39 Kumita, J. R., Poon, S., Caddy, G. L., Hagan, C. L., Dumoulin, M., Yerbury, J. J., Stewart, E. M., Robinson, C. V., Wilson, M. R. and Dobson, C. M. (2007) The extracellular chaperone clusterin potently inhibits human lysozyme amyloid formation by interacting with prefibrillar species. J Mol Biol. 369, 157-167

40 Yerbury, J. J., Poon, S., Meehan, S., Thompson, B., Kumita, J. R., Dobson, C. M. and Wilson, M. R. (2007) The extracellular chaperone clusterin influences amyloid formation and toxicity by interacting with prefibrillar structures. FASEB J. 21, 2312-2322

41 Johansson, J., Weaver, T. E. and Tjernberg, L. O. (2004) Proteolytic generation and aggregation of peptides from transmembrane regions: lung surfactant protein $\mathrm{C}$ and amyloid $\beta$-peptide. Cell Mol Life Sci. 61, 326-335

42 Mingarro, I., Nilsson, I., Whitley, P. and von Heijne, G. (2000) Different conformations of nascent polypeptides during translocation across the ER membrane. BMC Cell Biol. 1, 3

43 Eder, J. and Fersht, A. R. (1995) Pro-sequence-assisted protein folding. Mol Microbiol. 16, 609-614

44 Baker, D., Sohl, J. L. and Agard, D. A. (1992) A protein-folding reaction under kinetic control. Nature. 356, 263-265

45 Pepys, M. B., Hawkins, P. N., Booth, D. R., Vigushin, D. M., Tennent, G. A., Soutar, A. K., Totty, N., Nguyen, O., Blake, C. C., Terry, C. J., Feest, T. G., Zalin, A. M. and Hsuan, J. J. (1993) Human lysozyme gene mutations cause hereditary systemic amyloidosis. Nature. 362, 553-557

46 Nogee, L. M., Dunbar, A. E., 3rd, Wert, S. E., Askin, F., Hamvas, A. and Whitsett, J. A. (2001) A mutation in the surfactant protein $C$ gene associated with familial interstitial lung disease. N Engl J Med. 344, 573-579 


\section{FIGURE LEGENDS}

Fig. 1. Amino acid sequences of the constructs used for transient transfections. The numbering refers to positions in human proSP-C. HA, hemagglutinin tag. CTC-KDEL is preceded by a signal peptide from proSP-B (not shown).

Fig. 2. The proSP-C ${ }^{\mathrm{L} 188 \mathrm{Q}}$ and proSP-C $\mathrm{C}^{\mathrm{AExon4}}$ mutations give rise to amyloid-like deposits. (A) Congo red staining of HEK293 cells stably expressing wild type proSP-C (wt), proSP-C ${ }^{\mathrm{L} 188 \mathrm{Q}}$ (L188Q), or proSP$\mathrm{C}^{\Delta \mathrm{Exon} 4}(\Delta$ Exon4). Scale bars represent $10 \mu \mathrm{m}$. Arrows indicate Congo red positive protein deposits. Images are representative of experiments carried out two to four times, using duplicate samples of $0.5 \mathrm{x}$ $10^{6}$ cells per slide. (B), SDS-insoluble/formic acid soluble material from HEK293 cells stably expressing wild-type proSP-C, proSP-C $\mathrm{C}^{\mathrm{L} 188 \mathrm{Q}}$, proSP-C $\mathrm{C}^{\mathrm{173T}}$, or proSP-C $\mathrm{C}^{\Delta \mathrm{Exon} 4}$ immunoblotted with antibody directed against the C-terminal part of proSP-C. Equal amounts of total protein from cell extracts were used.

Fig. 3. CTC binds to and prevents aggregation and amyloid formation of proSP-C ${ }^{\mathrm{L} 188 \mathrm{Q}}$. (A) Congo red staining of HEK293 cells stably expressing proSP-C ${ }^{\mathrm{L} 188 \mathrm{Q}}$ (left panel) and the same cells after transient transfection with CTC-KDEL (right panel). Scale bars represent $20 \mu \mathrm{m}$. (B) Western blots of SDSinsoluble/formic acid soluble material in lysates of HEK293 cells stably expressing proSP-C ${ }^{\mathrm{L} 188 \mathrm{Q}}$. The cells in the lane labeled with a plus sign have been transiently transfected with a CTC-KDEL construct, whereas the cells in the lane labeled with a minus sign have been transfected with an empty vector. Equal amounts of total protein from cell extracts were used. (C) Co-precipitation experiments. HEK293 cells stably expressing proSP-C ${ }^{\mathrm{L} 188 \mathrm{Q}}$ or wild type proSP-C were transiently transfected with CTC-KDEL or empty vector (EV). Cell lysates were immunoprecipitated with antibody directed against N-terminal proSP-C and subsequently blotted with antibody directed against C-terminal proSP-C (left panel). As a control for equal inputs, whole cell lysates (right panel) were western blotted with antibody directed against C-terminal proSP-C. (D) Pulse-chase experiments in HEK293 cells. In upper panels, HEK293 cells were transiently transfected with CTC-KDEL, radio-labeled for $30 \mathrm{~min}$ and immunoprecipitated at the indicated chase times with antibody directed against C-terminal proSP-C (left panel) or N-terminal proSP-C (right panel), separated by SDS-PAGE and analysed by autoradiography. In the lower panels, HEK293 cells stably expressing proSP-C $\mathrm{C}^{\mathrm{L} 188 \mathrm{Q}}$ were transiently transfected with empty vector (left panel) or CTC-KDEL (right panel), subjected to pulse chase, and cell lysates immunoprecipitated with antibody directed against N-terminal proSP-C, followed by gel electrophoresis and autoradiography. In lower right panel, the upper band represents proSP-C $\mathrm{C}^{\mathrm{L} 188 \mathrm{Q}}$ and the lower band represents CTC that coprecipitates with proSP-C. The antibodies used for immunoprecipitations are indicated next to each panel.

Fig. 4. CTC prevents SP-C amyloid fibril formation. Negatively stained transmission electron micrographs of material from SDS-insoluble pellets of (A) SP-C surfactant incubated for 7 days, (B) SPC surfactant incubated for 14 days, (C) SP-C surfactant incubated for 7 days in the presence of CTC, and (D) polyLeu substituted SP-C surfactant incubated for 14 days. The figure in B is enlarged to show the fibrillar appearance of SP-C aggregates. Bars represent $100 \mathrm{~nm}$.

Fig. 5. CTC binds non-helical SP-C. MALDI mass spectra of (A) mixture of 11 pmol polyLeu substituted SP-C and 3 pmol CTC and (B) mixture of 11 pmol non-helical SP-C analogue and 3 pmol CTC. In A, peaks corresponding to singly charged monomer of CTC, doubly charged trimer of CTC, singly charged dimer of CTC, and singly charged trimer of CTC are labeled. In B, peaks corresponding to complexes between singly charged monomeric CTC and one, two, or three SP-C, and singly charged dimer of CTC and one or two SP-C are labeled.

Fig. 6. PolyVal $\rightarrow$ polyLeu substitution stabilises proSP-C C188Q $^{\text {(A) }}$ (A) Wern blots of lysates of HEK293 cells transiently transfected with a bicistronic vector encoding EGFP and wild type proSP-C 
(lane 1), proSP-C(Leu) (lane 2), proSP-C $\mathrm{C}^{\mathrm{L} 188 \mathrm{Q}}$ (lane 3) or proSP-C(Leu) ${ }^{\mathrm{L} 188 \mathrm{Q}}$ (lane 4). The top panel shows a Western blot with antibody directed against mature SP-C. The blot in the top panel was serially stripped and reprobed with antibody directed against proSP-C (middle panel) or GFP (bottom panel). The upper band is GFP and the lower band is incompletely stripped proSP-C (bottom panel). (B) Formic acid soluble, SDS-insoluble material from HEK293 cells transiently transfected with proSP-C ${ }^{\mathrm{L} 188 \mathrm{Q}}$ or proSP$\mathrm{C}(\mathrm{Leu})^{\mathrm{L} 188 \mathrm{Q}}$ immunoblotted with antibody directed against N-terminal proSP-C. Equal amounts of total protein from proSP-C ${ }^{\mathrm{L} 188 \mathrm{Q}}$ (left lane, Val) and proSP-C(Leu) ${ }^{\mathrm{L} 188 \mathrm{Q}}$ (right lane, Leu) cell extracts were used.

Fig. 7. Model of maturation of newly synthesized proSP-C and effects of Brichos mutations. (A) Wild type proSP-C in which the CTC Brichos domain interacts with poly-Val segments until they have folded into transmembrane helices. (B) Proposed effects of Brichos domain mutations that abrogate interaction with unfolded poly-Val segments and thereby allow formation of amyloid-like aggregates. ProSP-C contains four domains; the N-terminal propart (residues 1-23, green), the transmembrane domain that corresponds to mature SP-C (residues 24-58, red), the Brichos domain (residues 94-197, blue), and a segment that links the transmembrane domain and the Brichos domain (residues 59-93, black). 
Figure 1

proSP $-C$
proSP $-C^{\mathrm{L} 1880}$
proSP -C (Leu)
proSP-C (Leu)
CTC-KDE

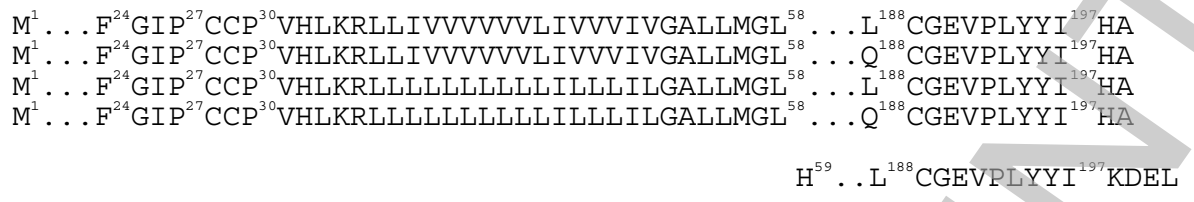


Figure 2

A

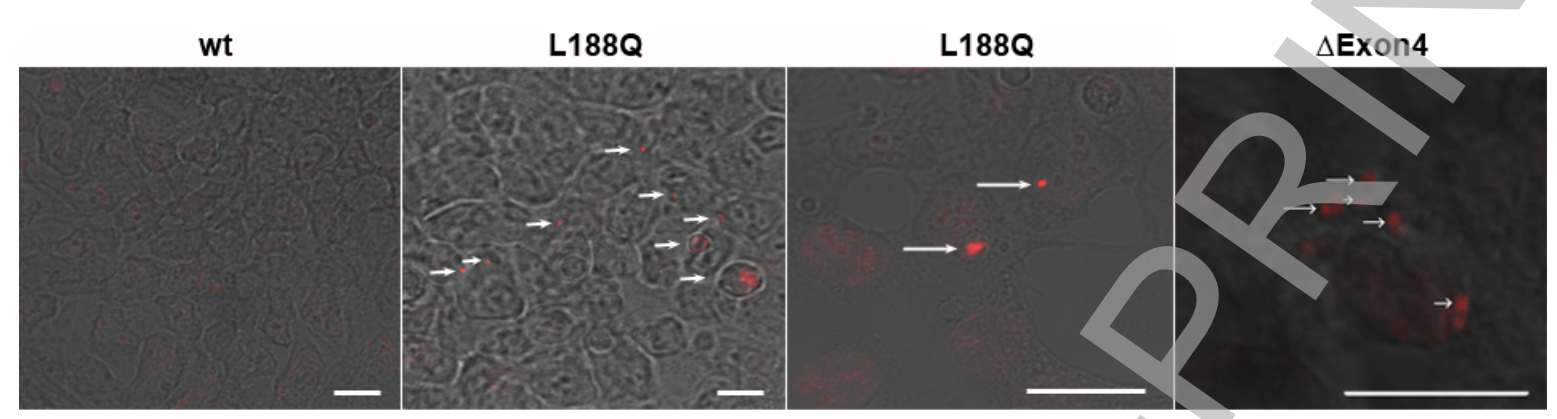

B

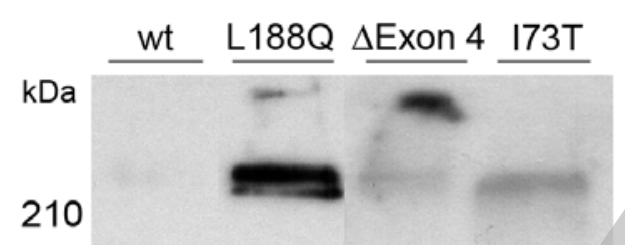

78

55

45

17

Licenced copy. Copying is not permitted, except with prior permission and as allowed by law. (C) 2008 The Authors Journal compilation (c) 2008 Biochemical Society 
Figure 3

A

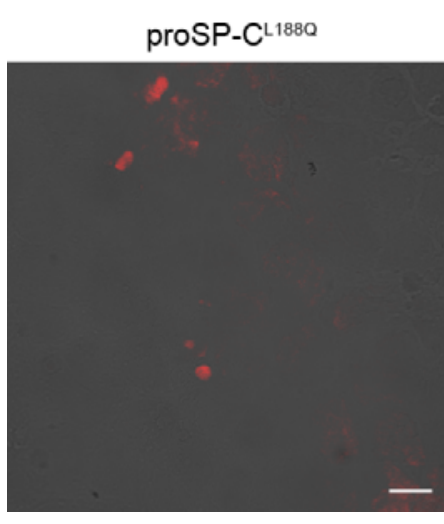

proSP-C ${ }^{L 1880}+$ CTC

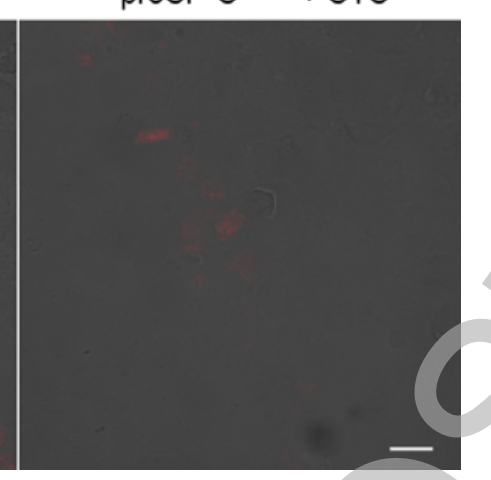

C
B

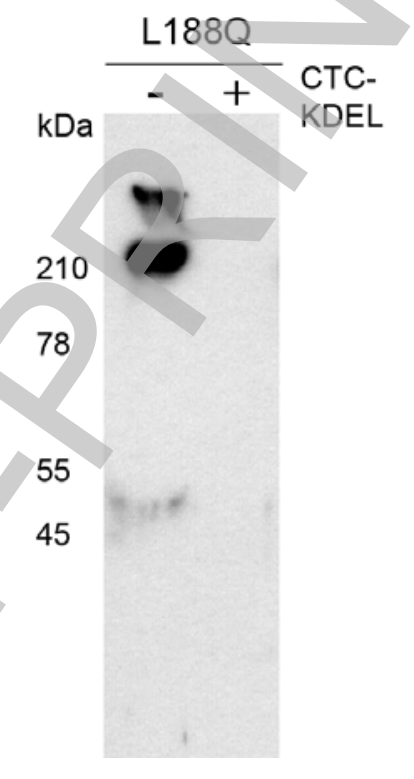

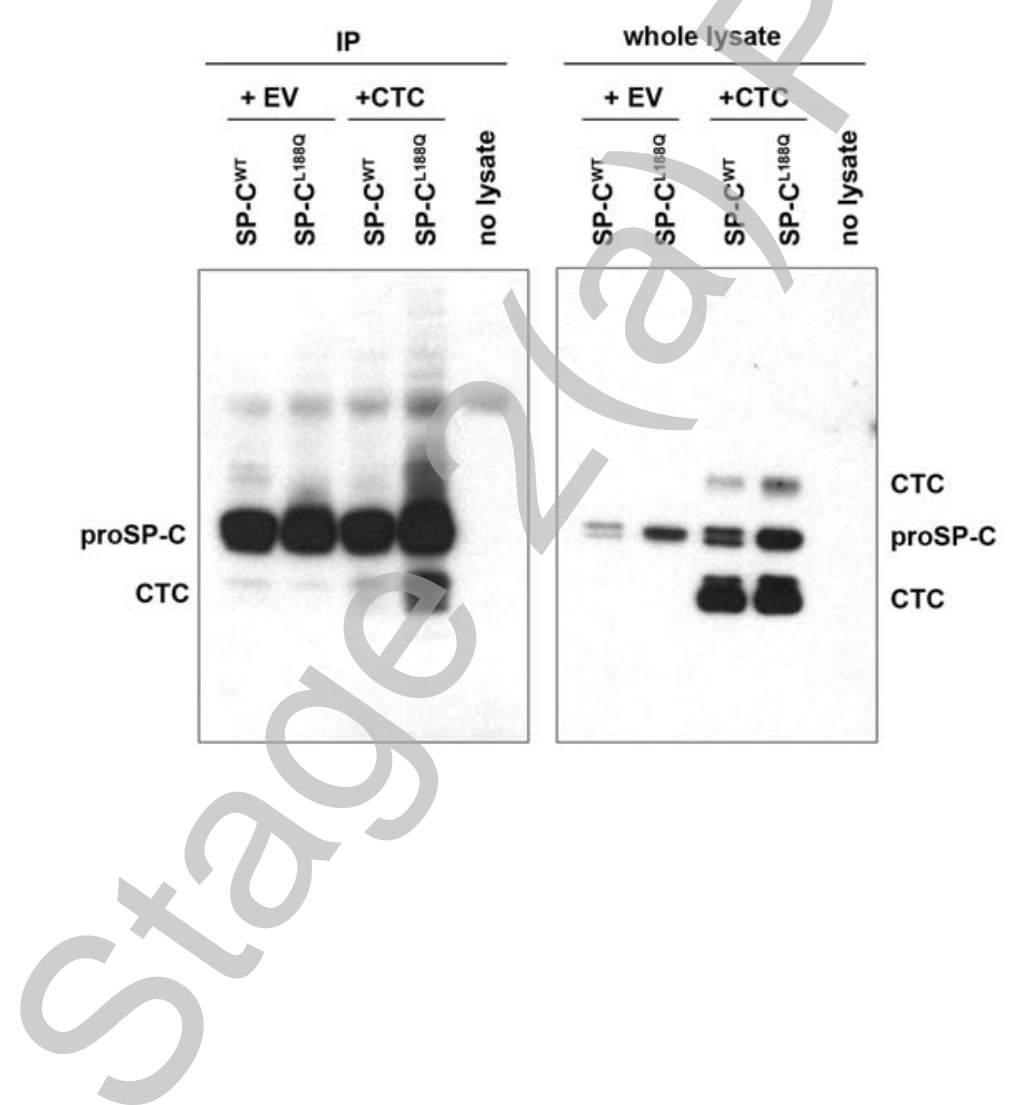




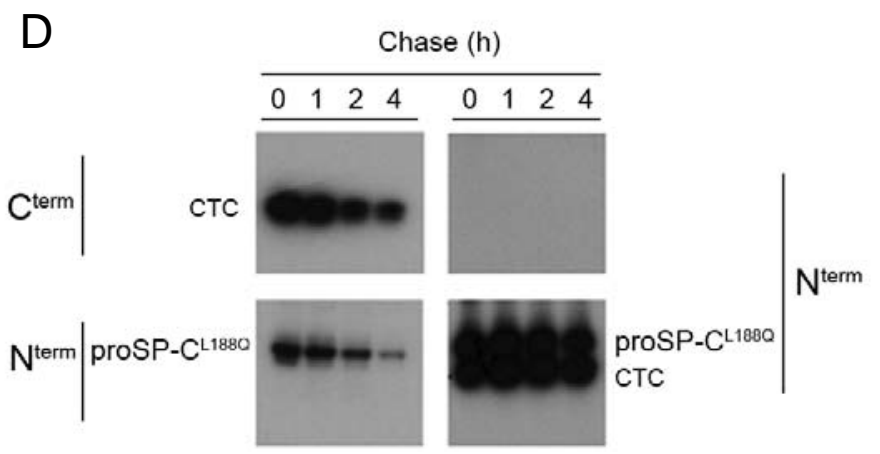


Figure 4

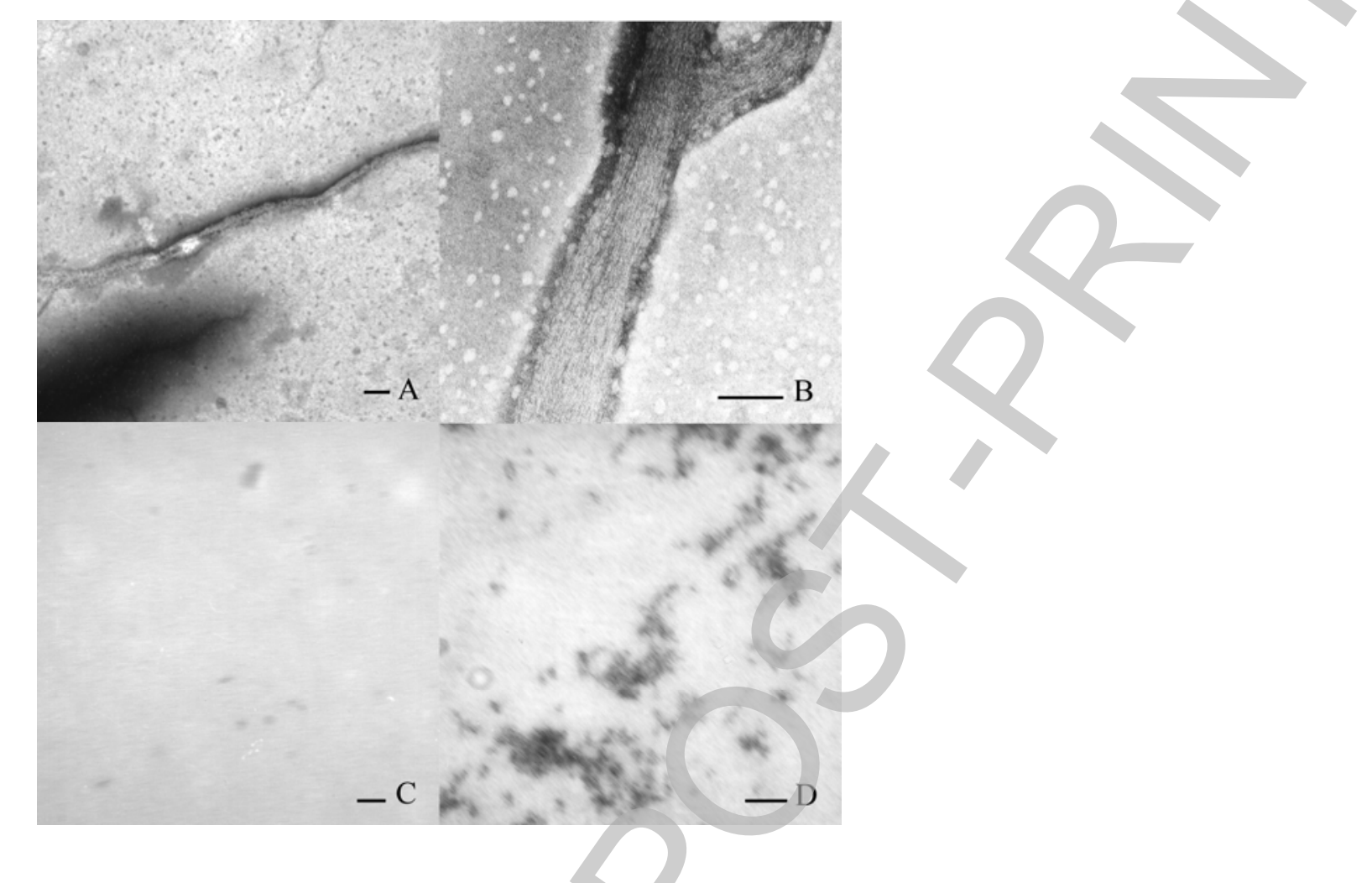


Figure 5

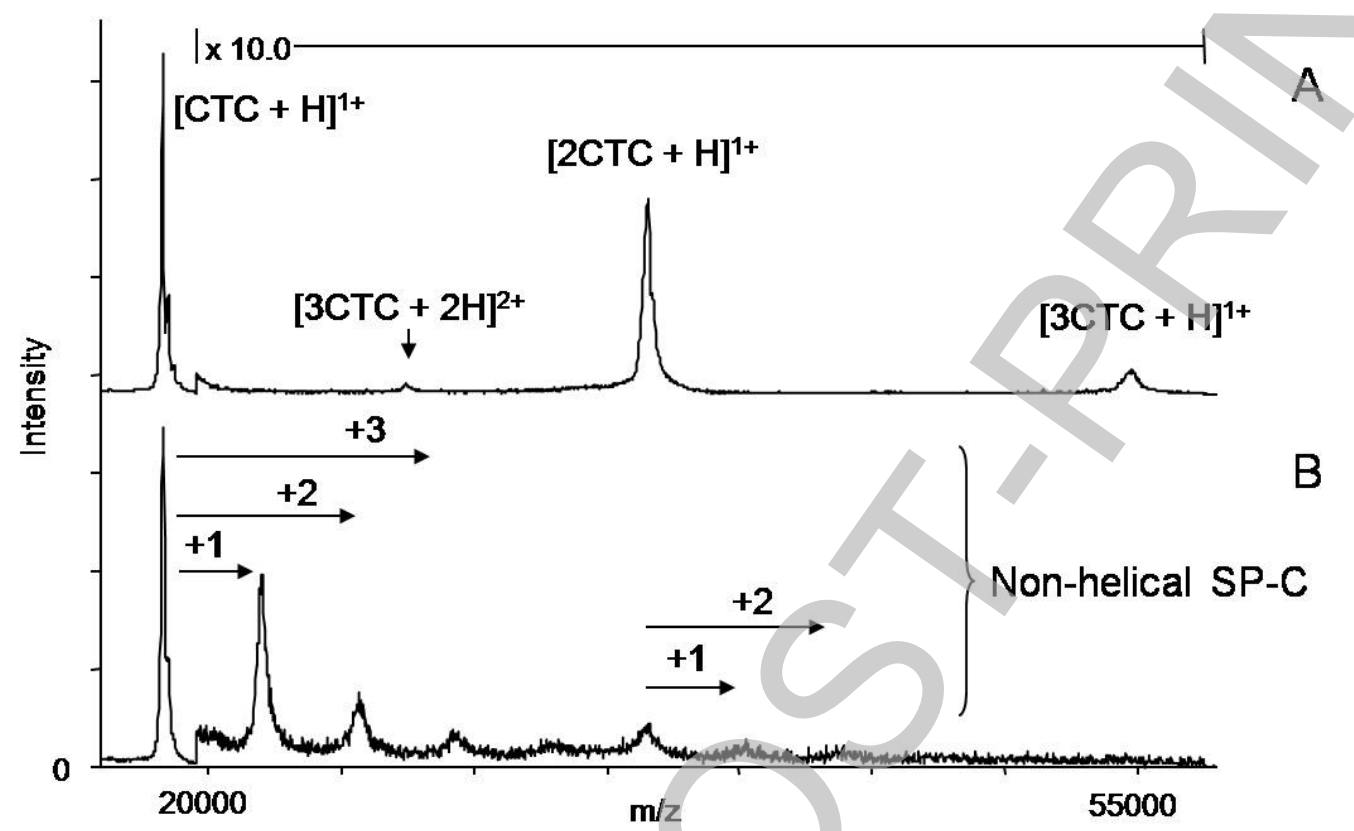


Figure 6

A
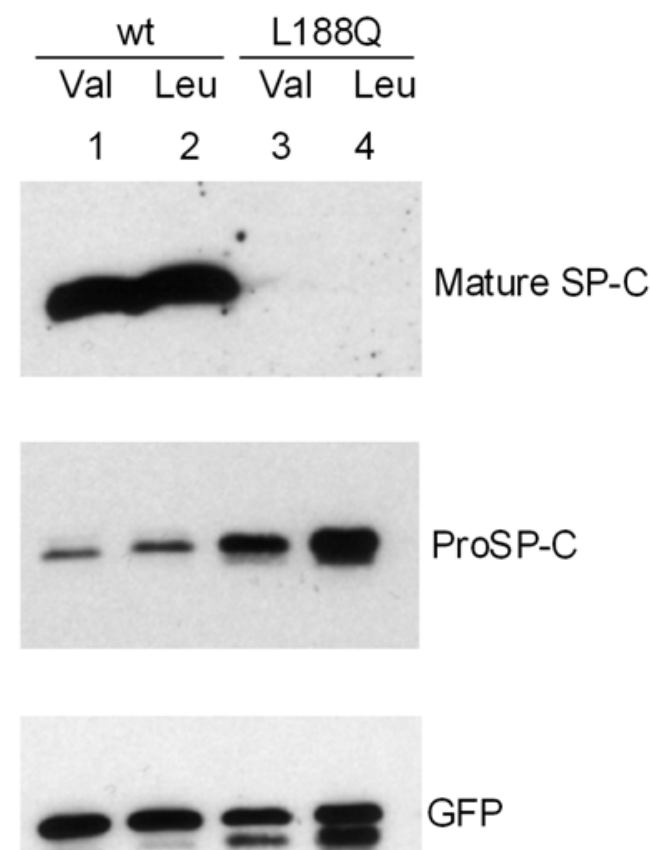

B

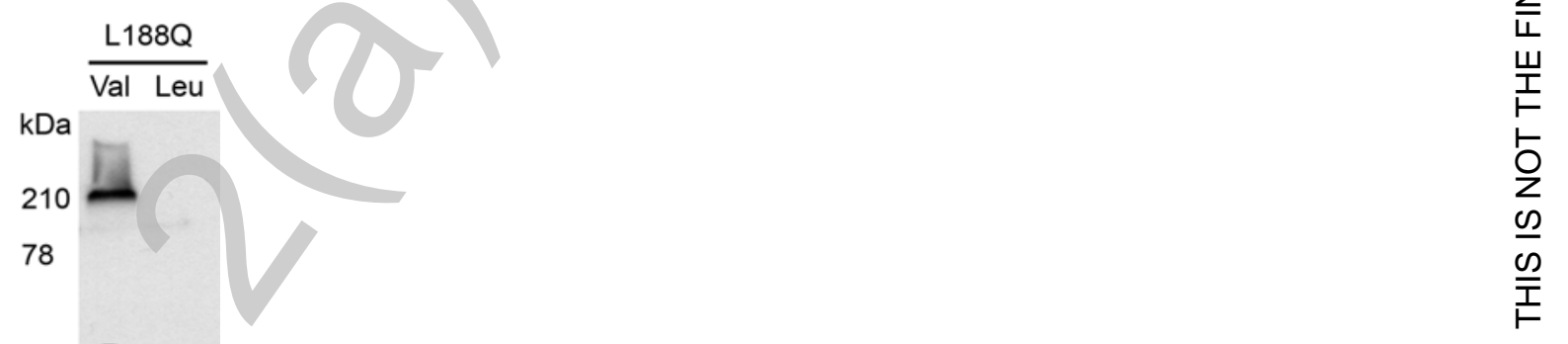


Figure 7
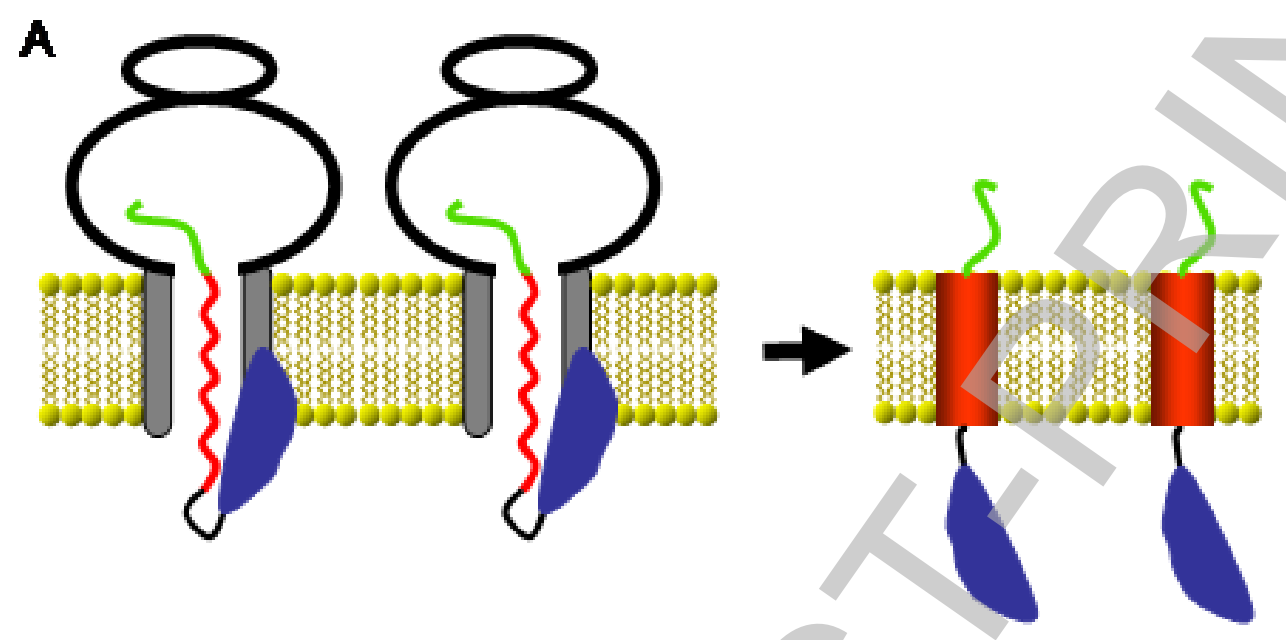

B

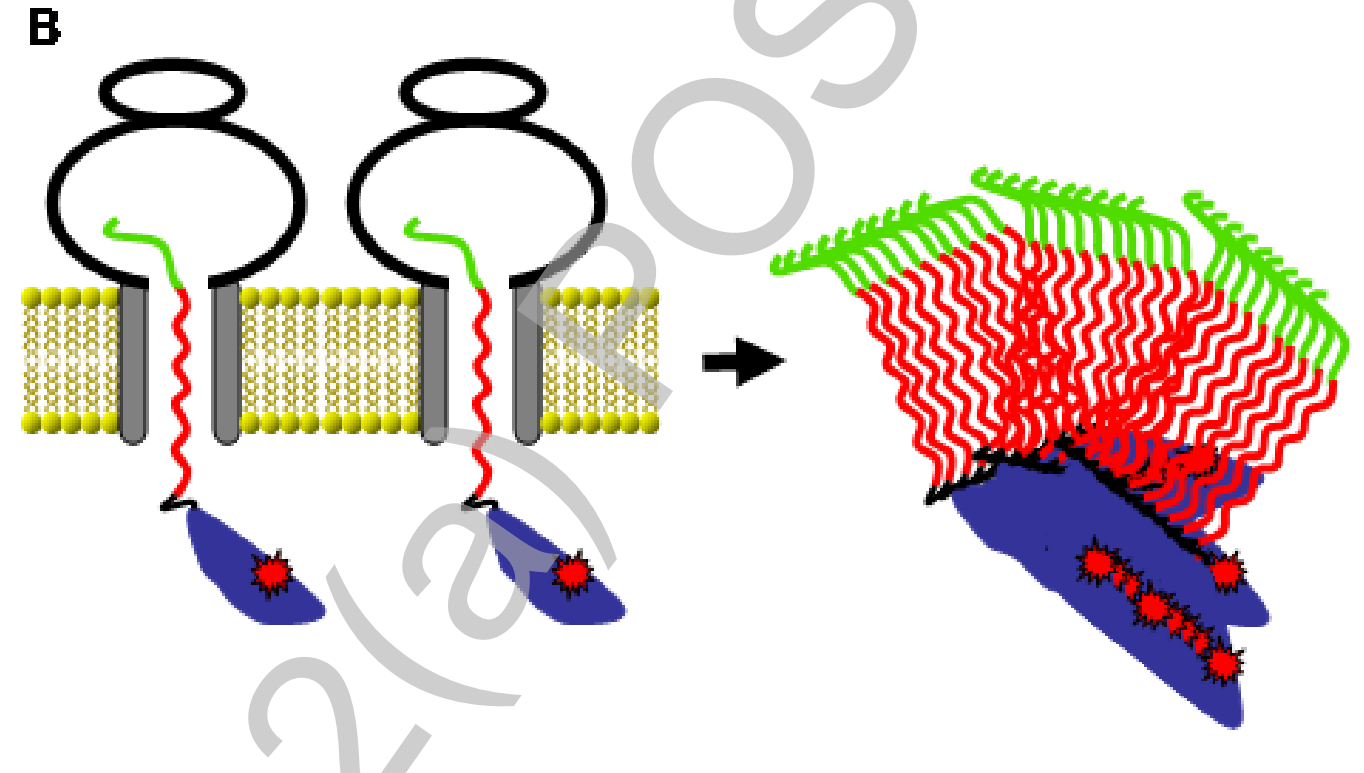

